\title{
The journey of the heart failure patient, based on data from a single center
}

\author{
Anna Chuda ${ }^{B-D}$, Joanna Berner ${ }^{B-D}$, Małgorzata Lelonek ${ }^{A, E, F}$ \\ Department of Noninvasive Cardiology, Chair of Internal Medicine and Cardiology, Medical University of Lodz, Poland \\ A - research concept and design; $\mathrm{B}$ - collection and/or assembly of data; $\mathrm{C}$ - data analysis and interpretation; \\ $D$ - writing the article; $E$ - critical revision of the article; $F$ - final approval of the article
}

Address for correspondence

Małgorzata Lelonek

E-mail:malgorzata.lelonek@umed.lodz.pl

Funding sources

None declared

Conflict of interest

None declared

\section{Acknowledgements}

Authors would like to thank Patryk Łęczycki

for his assistance in collecting data presented

in this article.

Received on May 8, 2017

Reviewed on August 27, 2017

Accepted on 0ctober 17, 2017

Published online on 0ctober 2, 2018

Cite as

Chuda A, Berner J, Lelonek M. The journey of the heart failure patient, based on data from a single center. Adv Clin Exp Med. 2019;28(4):489-498. doi:10.17219/acem/78688

DOI

10.17219/acem/78688

Copyright

Copyright by Author(s)

This is an article distributed under the terms of the

Creative Commons Attribution Non-Commercial License

(http://creativecommons.org/licenses/by-nc-nd/4.0/)

\section{Abstract}

Background. Care for patients with heart failure (HF) in Poland requires improvement.

Objectives. The aim of this study was to define the journey of the HF patient, taking into account the specialization of the hospital ward and further, highly specialized outpatient care.

Material and methods. Using the medical system CliniNE ${ }^{\circledR}$, we analyzed 214 consecutive patients hospitalized due to HF (International Statistical Classification of Diseases and Health Related Problems - ICD-10: I50) in the period from September 1 to December 31, 2015, and also the data from post-discharge outpatient care in a 3-month period. To fairly compare the management of care and outcomes of patients hospitalized in the internal medicine (IM) ward and in the cardiac ward, propensity score matching was performed. The multivariate regression analysis was performed to determine the independent predictors of the hospital ward selection and the risk of rehospitalization due to $\mathrm{HF}$ and/or death.

Results. The majority of patients were hospitalized due to HF for the first time (72\%) and in the cardiac ward (65\%). For $55 \%$ of rehospitalized patients, the subsequent admission was within 3 months after initial discharge. The independent predictors of a higher risk of rehospitalization due to HF and/or death were ischemic heart disease, atrial fibrillation (AF), chronic kidney disease (CKD), mineralocorticoid antagonism (MRA) therapy, and hospitalization in the last year (for all, $p<0.05$ ). Internal medicine ward patients differed from cardiac ward patients in: mode of admission (urgent $100 \%$ vs $83.5 \% ; p<0.001$ ), length of hospitalization (median: 8 days vs 5 days; $p=0.001$ ), death rate ( $24 \%$ vs $4.3 \% ; p<0.001$ ), echocardiography ( $43 \%$ vs $98 \%$; $p<0.001$ ), and N-terminal prohormone B-type natriuretic peptide (NT-proBNP) measurements (43\% vs 96\%; $p<0.001)$. The burden of $5-9$ accompanying diseases enhanced the choice of the cardiac ward $(p<0.05)$, while age and urgent mode of hospitalization decreased the chance of being referred to the cardiac ward $(p<0.01)$. Cardiac patients were more likely to receive $\beta$-blockers, diuretics, angiotensin receptor blockers (ARB), and MRA. Over $90 \%$ of cardiac ward patients were referred to cardiac ambulatory care after discharge from hospital, while among patients discharged from the IM ward, this rate was $60 \%(p<0.001)$.

Conclusions. There were significant differences among the 2 wards in relation to the course of hospitalization and post-discharge outpatient care.

Key words: heart failure, hospitalization, cardiology, internal medicine 


\section{Introduction}

Nowadays, heart failure (HF) is a major health issue, as it is associated with high prevalence, high death rates and large consumption of healthcare resources. ${ }^{1,2}$ Heart failure affects approx. $1-2 \%$ of adults in developed countries. ${ }^{3}$ Its prevalence rises significantly with age and, according to the latest data, the morbidity will further increase. ${ }^{4} \mathrm{Al}$ together, 1/5 of adult individuals will develop HF at some point. 5

It is estimated that $30 \%$ of HF patients are readmitted to hospital within 60-90 days from initial hospitalization. ${ }^{6,7}$ In European studies, reported HF rehospitalization rates ranged from $24 \%$ at 12 weeks to $44 \%$ after 1 year post-discharge and had poor prognosis. ${ }^{8,9}$ In their study, Solomon et al. proved that the death rate in HF patients increased by $30 \%$ after the $2^{\text {nd }}$ and $3^{\text {rd }}$ readmission. ${ }^{10} \mathrm{Ap}$ proximately $10 \%$ of HF patients die 60-90 days post-discharge. ${ }^{11,12}$ In Poland, 164 patients die every day due to HF, which amounts to over 60,000 deaths annually. ${ }^{13}$

According to the Organisation for Economic Co-operation and Development (OECD) 2015 report, Poland has the highest number of hospitalizations due to HF in the world. ${ }^{2}$ The high numbers of hospitalizations for HF are a huge burden for healthcare systems. In 2012, the costs of HF patients' management reached 672 million PLN, of which 94\% were hospitalization costs. ${ }^{13}$ Analyzing the economic and social costs in 2012, Gierczyński et al. documented that $75 \%$ of HF patients were hospitalized at internal medicine (IM) wards and $22 \%$ at cardiac wards. ${ }^{13}$ This fact became the basis of the hypothesis that there are differences related to the admission ward in terms of the characteristics of the hospitalized patient, diagnostic procedures, as well as in-hospital and post-discharge care.

The aim of this analysis was to assess the journey of the HF patient in Poland, based on the single-center experience, including the type of the admission ward and further cardiac outpatient care.

\section{Material and methods}

The study was designed as a questionnaire retrospective survey. It was conducted using questionnaire authoring, available in the electronic form. The standardized study questionnaires were designed to collect information on general characteristics of the patient group and to evaluate the HF patient management in the cardiac ward and the IM ward in the period from September 1 to December 31, 2015, in the Central Hospital of Medical University of Lodz, Poland, based on the available medical records. The survey was conducted using the medical system CliniNET $^{\circledR}$. The field studies dealt with the data on post-discharge outpatient care from the time of discharge to March 31, 2016. The questionnaire was constructed according to the applicable standards and rules concerning the collection of data through a survey. The questions concerned the demographics, etiology and history of HF, the results of laboratory tests, applied treatment, death during or after hospitalization, and data on post-discharge outpatient care in a 3-month period. The data in the registry was verified and entered by specially trained physicians.

At baseline, the study included 214 consecutive patients. The inclusion criteria were as follows: hospitalization with I50 diagnostic code in the International Statistical Classification of Diseases and Health Related Problems (ICD-10) classification, hospitalization in the cardiac or IM ward in the Central Hospital of Medical University of Lodz, Poland, and hospitalization in the period from September 1 to December 31, 2015.

The study excluded patients hospitalized in the cardiac or IM ward with a diagnostic code other than I50 in the ICD-10 classification and patients hospitalized in other period. The structure of the study sample is presented in Table 1. The analyzed wards were researched regarding the medical

Table 1. Characteristics of the study population

\begin{tabular}{|c|c|}
\hline Age [years], mean $\pm \mathrm{SD}$ & $72.2 \pm 12.9$ \\
\hline Males, n [\%] & $105(49.1)$ \\
\hline BMI [kg/m²], median (IQR) & $27.4(24.28-31.2)^{\mathrm{a}}$ \\
\hline SBP [mm Hg], median (IQR) & $130(115-140)^{a}$ \\
\hline DBP [mm Hg], median (IQR) & $78(70-85)^{a}$ \\
\hline Urgent mode of admission, n [\%] & $191(89.2)$ \\
\hline Arterial hypertension, n [\%] & $162(75.7)$ \\
\hline Coronary artery disease, $\mathrm{n}[\%]$ & $100(46.7)$ \\
\hline History of myocardial infarction, n [\%] & $54(25.2)$ \\
\hline$C K D, n[\%]$ & $48(22.4)$ \\
\hline $\mathrm{AF}, \mathrm{n}[\%]$ & $109(50.9)$ \\
\hline $\mathrm{DM}, \mathrm{n}[\%]$ & $90(42.1)$ \\
\hline COPD, n [\%] & $30(14.0)$ \\
\hline Cancer, n [\%] & $15(7.0)$ \\
\hline ICD, n [\%] & $15(7.0)$ \\
\hline CRT, n [\%] & $7(3.3)$ \\
\hline LVEF [\%], mean \pm SD & $42.2 \pm 16.8$ \\
\hline NT-proBNP on admission [pg/mL], median (IQR) & $3,356(2,204-10,341)^{\mathrm{a}}$ \\
\hline $\mathrm{Hb}[\mathrm{g} / \mathrm{dL}]$, median (IQR) & $12.9(11-13.9)^{a}$ \\
\hline Sodium [mmol/L], median (IQR) & $138.1(133-143.2)^{\mathrm{a}}$ \\
\hline Creatinine $[\mu \mathrm{mol} / \mathrm{L}]$, median $(\mathrm{IQR})$ & $98(80.5-111.5)^{a}$ \\
\hline eGFR $\left[\mathrm{mL} / \mathrm{min} / 1.73 \mathrm{~m}^{2}\right]$, median (IQR) & $61.4(47.75-75.75)^{a}$ \\
\hline Fasting glucose $[\mathrm{mmol} / \mathrm{L}]$, median $(\mathrm{IQR})$ & $6(5.07-7.41)^{a}$ \\
\hline CRP [mg/L], median (IQR) & $7.2(2.9-21.8)^{a}$ \\
\hline Coronary angiography, n [\%] & $22(10.3)$ \\
\hline
\end{tabular}

Data is presented as mean \pm standard deviation (SD), median (interquartile range - IQR) or number (percentage). ${ }^{a}$ Variables with non-parametric distribution. AF - atrial fibrillation; BMI - body mass index; CKD - chronic kidney disease; COPD - chronic obstructive pulmonary disease; CRP - C-reactive protein; CRT - cardiac resynchronization therapy; DBP - diastolic blood pressure; DM - diabetes mellitus; eGFR - estimated glomerular filtration rate; $\mathrm{Hb}$ - hemoglobin; ICD - implantable cardioverter defibrillator; LVEF - left ventricle ejection fraction; NT-proBNP - N-terminal prohormone B-type natriuretic peptide: SBP - systolic blood pressure. 
records of the hospitalized patients with the final HF diagnosis.

The patients' medical history was taken, a physical examination was performed and basic laboratory results were assessed in all study patients on admission. The clinical symptoms of HF were classified according to the New York Heart Association (NYHA). ${ }^{14}$

Echocardiographic measurements were performed according to the guidelines of the American Society of Echocardiography (ASE) and European Association of Echocardiography (EAE). ${ }^{15}$ A coronary arteriography was performed as needed according to the ASE/EAE and European Society of Cardiology (ESC) recommendations. ${ }^{16}$ Heart failure with reduced ejection fraction (HFrEF) was diagnosed when the left ventricle ejection fraction (LVEF) measurement was less than $40 \% .{ }^{17}$ Heart failure with preserved ejection fraction (HFpEF) was diagnosed when the LVEF measurement remained greater than $50 \% .^{17}$

The following parameters were analyzed in this study:

- age, gender, body mass index (BMI), arterial blood pressure, coincidence of arterial hypertension, diabetes mellitus (DM), myocardial infarction, coronary artery disease, atrial fibrillation (AF), renal failure, chronic obstructive pulmonary diseases (COPD), cancer, coronary artery bypass graft (CABG), and electrotherapy history: cardiac resynchronization therapy $(\mathrm{CRT}) /$ implantable cardioverter defibrillator (ICD);

- HF etiology (ischemic vs non-ischemic: hypertension, valvular disease, congestive cardiomyopathy, myocarditis, toxic cardiomyopathy, tachyarrhythmic cardiomyopathy) and past history of HF;

- mode (urgent vs planned) and length of current hospitalization;

- selected laboratory results: hemoglobin $(\mathrm{Hb})$, sodium, potassium, creatinine, estimated glomerular filtration rate (eGFR), C-reactive protein (CRP), fasting glucose, and $\mathrm{N}$-terminal prohormone $\mathrm{B}$-type natriuretic peptide (NT-proBNP);

- electrocardiography (ECG) variables: heart rhythm, heart rate (HR), left bundle branch block (LBBB);

- selected echocardiographic results, including LVEF;

- coronary arteriography results;

- drugs and doses of standard HF therapy prescribed at discharge: angiotensin-converting-enzyme inhibitors (ACEI), angiotensin receptor blockers (ARB), $\beta$-blockers, mineralocorticoid antagonist (MRA), ivabradine, and diuretics;

- death during or after hospitalization;

- post-discharge outpatient care.

The collected data was subjected to hospital ward- and endpoint-related statistical analysis. The endpoints were as follows: HF rehospitalization and/or death.

Statistical analysis was conducted using the statistical package STATISTICA PL v. 10.0 (StatSoft Polska Sp. z o.o., Kraków, Poland). Continuous variables were first evaluated for normal distribution using the Shapiro-Wilk test. We also checked data distribution. The Mann-Whitney test was used to compare continuous variables. All continuous variables were expressed as mean, median, interquartile range (IQR, Q25-Q75), and standard deviation (SD); categorical variables were expressed as the number of observations (n) and the corresponding percentage (\%). The $\mathrm{X}^{2}$ test was used to compare the qualitative data between the groups. Fisher's exact test for independence (in lower numbers) was used. The odds ratio (OR) and a 95\% confidence interval $(95 \% \mathrm{CI})$ were assigned. All statistical tests were two-sided. All variables significantly associated $(\mathrm{p}<0.05)$ with the selection of a hospital ward and a higher risk of rehospitalization and/or death in the univariate model were included in the multivariate regression analysis to determine the independent predictors of the hospital ward selection and the risk of rehospitalization and/or death. Results were considered statistically significant at $\mathrm{p}<0.05$. All tables present only the variables which differ or have been selected in the context of the article.

The study design was approved by the Bioethics Committee of Medical University of Lodz, Poland (No. RNN/38/16/KE).

Data was collected and processed maintaining confidentiality of the patients and physicians participating in the study.

To adequately compare the management of care and outcomes of the patients hospitalized in the 2 wards, we had to create identical groups of patients in terms of the epidemiological data, frequency of comorbidities, etiology of HF, and clinical status on admission to hospital, by means of propensity score matching.

\section{Results}

The final study sample included 214 patients. Detailed characteristics of the study population are presented in Table 1. The studied cohort suffered the most common comorbidities including: arterial hypertension, AF, coronary artery disease, DM, and chronic kidney disease (CKD).

The majority of the studied patients were admitted in an urgent mode ( $\mathrm{n}=191 ; 89 \%$ ) and hospitalized in the cardiac ward ( $\mathrm{n}=139 ; 65 \%)$. Comparing to cardiac ward patients, IM ward patients were older, more likely to have accompanying infection, as well as higher systolic blood pressure (SBP) and HR at discharge (Table 2). Internal medicine ward patients had less devices - ICD $(1.3 \%$ vs $10 \%$; $\mathrm{p}=0.035)$ or CRT (0 vs $5 \%$; p $=0.099$ ) and history of myocardial infarction (10.7\% vs $33 \%$; $\mathrm{p}=0.001)$.

According to the results of the univariate analysis, the significant variables for choosing the cardiac ward on admission were as follows: sex, age, mode of hospitalization (urgent vs planned), number of comorbidities, AF, and LVEF ( $>40 \%$ vs $\leq 40 \%$ ). The multivariate regression analysis revealed the independent predictors of choosing the cardiac ward (Table 3). The burden of 5-9 accompanying diseases enhanced the choice of the cardiac ward more than 5-fold (Table 3), while age and urgent mode 
Table 2. Comparison between hospitalizations in cardiac and internal medicine (IM) wards

\begin{tabular}{|c|c|c|c|}
\hline Variables & Cardiac ward & IM ward & p-value \\
\hline All patients, n [\%] & $139(65.8)$ & $75(35.0)$ & - \\
\hline Males, n [\%] & $76(54.7)$ & $29(38.7)$ & 0.591 \\
\hline Age [years], median (IQR) & $72.0(62.0-80.0)^{a}$ & $81.0(72.0-86.0)^{a}$ & $<0.001$ \\
\hline $\mathrm{BMI}\left[\mathrm{kg} / \mathrm{m}^{2}\right]$, mean $\pm \mathrm{SD}$ & $28.75 \pm 6.1$ & $27.99 \pm 5.8$ & 0.611 \\
\hline SBP [mm Hg], median (IQR) & $126(110-140)^{a}$ & $135(120-140)^{a}$ & 0.007 \\
\hline $\mathrm{DBP}[\mathrm{mm} \mathrm{Hg}]$, median (IQR) & $75(66-80)^{\mathrm{a}}$ & $80(70-85)^{a}$ & 0.092 \\
\hline HR on admission [bpm], median (IQR) & $76(70-90)^{a}$ & $880(70-100)^{a}$ & 0.168 \\
\hline HR at discharge [bpm], median (IQR) & $70(64-75)^{a}$ & $76(70-80)^{a}$ & $<0.001$ \\
\hline \multicolumn{4}{|c|}{ Comorbidities } \\
\hline Underweight, n [\%] & 0 & $2(4.4)$ & 0.142 \\
\hline Overweight, n [\%] & $52(38.8)$ & $14(31.1)$ & 0.142 \\
\hline Obesity, n [\%] & $42(31.3)$ & $15(33.3)$ & 0.142 \\
\hline Coronary artery disease, n [\%] & $71(51.1)$ & $29(38.7)$ & 0.111 \\
\hline $\mathrm{AF}, \mathrm{n}[\%]$ & $73(52.5)$ & $36(48.0)$ & 0.626 \\
\hline $\mathrm{DM}, \mathrm{n}[\%]$ & $57(41.0)$ & $33(44.0)$ & 0.781 \\
\hline Arterial hypertension, n [\%] & $108(77.7)$ & $54(72.0)$ & 0.447 \\
\hline$C K D, n[\%]$ & $27(19.4)$ & $21(28.0)$ & 0.207 \\
\hline COPD, n [\%] & $18(12.9)$ & $12(16.0)$ & 0.684 \\
\hline Cancer, n [\%] & $8(5.8)$ & $7(9.3)$ & 0.485 \\
\hline Infection, n [\%] & $20(14.4)$ & $33(44.0)$ & $<0.001$ \\
\hline \multicolumn{4}{|c|}{ Current hospitalization } \\
\hline Urgent hospitalization, n [\%] & $116(83.5)$ & $75(100)$ & $<0.001$ \\
\hline Length of hospitalization [days], median (IQR) & $5(3-8)^{a}$ & $8(5-10)^{a}$ & 0.001 \\
\hline Death in-hospital, n [\%] & $4(2.9)$ & $15(20.0)$ & $<0.001$ \\
\hline Death post-discharge, $n$ [\%] & $2(1.4)$ & $3(4.0)$ & $<0.001$ \\
\hline \multicolumn{4}{|c|}{ Access to ambulatory care } \\
\hline Referral to a cardiology outpatient clinic, n [\%] & $127(91.9)$ & $45(60.0)$ & $<0.001$ \\
\hline Control visit in a cardiology clinic, n [\%] & $44(35.5)$ & $7(18.9)$ & 0.089 \\
\hline$<1$ month, $\mathrm{n}[\%]$ & $16(36.4)$ & $1(14.3)$ & 0.007 \\
\hline $1-3$ months, $\mathrm{n}[\%]$ & $9(20.5)$ & 0 & 0.007 \\
\hline unknown, n [\%] & $4(9.1)$ & $5(71.4)$ & 0.007 \\
\hline \multicolumn{4}{|c|}{ Pharmacotherapy } \\
\hline $\mathrm{ACEl}, \mathrm{n}[\%]$ & $87(62.6)$ & $42(56.0)$ & 0.427 \\
\hline $\mathrm{ARB}, \mathrm{n}[\%]$ & 27 (19.4) & $5(6.7)$ & 0.022 \\
\hline$\beta$-blockers, n [\%] & $124(89.2)$ & $55(73.3)$ & 0.005 \\
\hline MRA, n [\%] & $47(85.5)$ & $5(50.0)$ & 0.022 \\
\hline Ivabradine, n [\%] & $4(26.7)$ & 0 & 1.000 \\
\hline Diuretics, n [\%] & $120(86.3)$ & $52(69.3)$ & 0.005 \\
\hline
\end{tabular}

Data is presented as mean \pm standard deviation (SD), median (interquartile range - IQR) or number (percentage). A p-value $<0.05$ is considered statistically significant. ${ }^{a}$ Variables with nonparametric distribution. A p-value $<0.05$ is considered statistically significant. ACEI - angiotensin-converting-enzyme inhibitors; AF - atrial fibrillation; ARB - angiotensin receptor blockers; BMI - body mass index; CKD - chronic kidney disease; COPD - chronic obstructive pulmonary disease; DBP - diastolic blood pressure; DM - diabetes mellitus; HR - heart rate; IM - internal medicine; MRA - mineralocorticoid antagonism; $\mathrm{SBP}$ - systolic blood pressure.

of hospitalization decreased the chance of choosing the cardiac ward (Table 3).

As compared to IM ward patients, cardiac ward patients were more likely to undergo echocardiography (98\% vs 43\%; $\mathrm{p}<0.001$ ) and the measurements of NT-proBNP concentration $(96 \%$ vs $43 \%$; $<<0.001)$. For the whole population, the median NT-proBNP concentration was high, with a median of $3356 \mathrm{pg} / \mathrm{mL}$ (IQR = 2,204-10,341). Based on the available echocardiography results $(n=168)$, the mean LVEF was $42.2 \pm 16.8 \%$. Among patients with ejection fraction (EF) data, 44.04\% had HFpEF and 55.96\% had HFrEF. Based on the available ECG results $(n=212)$, 
Table 3. Results of the multivariate regression models

\begin{tabular}{|c|c|c|c|c|}
\hline Variables & $\operatorname{Exp}(B)-O R$ & \multicolumn{2}{|c|}{$95 \% \mathrm{Cl}$ for OR } & $p$-value \\
\hline \multicolumn{5}{|c|}{ Choice of the cardiac ward } \\
\hline Sex: women vs men & 0.83 & 0.33 & 2.09 & 0.689 \\
\hline Age [years] & 0.93 & 0.91 & 0.96 & $<0.001$ \\
\hline $\begin{array}{l}\text { Number of comorbidities: } \\
1-3 \\
3-5 \\
5-9\end{array}$ & $\begin{array}{l}1.52 \\
2.15 \\
5.46\end{array}$ & $\begin{array}{l}0.53 \\
0.71 \\
1.20\end{array}$ & $\begin{array}{r}4.31 \\
6.45 \\
24.85\end{array}$ & $\begin{array}{l}0.436 \\
0.174 \\
0.028\end{array}$ \\
\hline $\begin{array}{l}\text { Mode of hospitalization: } \\
\text { urgent vs planned }\end{array}$ & 0.31 & 0.14 & 0.67 & 0.003 \\
\hline AF & 1.25 & 0.51 & 3.06 & 0.631 \\
\hline $\begin{array}{l}\text { LVEF: } \\
>40 \% \text { vs } \leq 40 \%\end{array}$ & 0.90 & 0.35 & 2.34 & 0.832 \\
\hline \multicolumn{5}{|c|}{ Rehospitalization and/or mortality } \\
\hline Ischemic heart disease & 4.65 & 1.32 & 16.34 & 0.017 \\
\hline $\mathrm{AF}$ & 5.24 & 1.81 & 15.13 & 0.004 \\
\hline Arterial hypertension & 0.13 & 0.05 & 0.36 & $<0.001$ \\
\hline Valvular disease & 0.47 & 0.19 & 1.16 & 0.102 \\
\hline CKD & 3.62 & 1.06 & 12.30 & 0.04 \\
\hline $\begin{array}{l}\text { The number of comorbidities: } \\
0-3 \text { vs 3-8 }\end{array}$ & 0.37 & 0.11 & 1.27 & 0.115 \\
\hline MRA therapy & 2.57 & 1.05 & 6.26 & 0.038 \\
\hline $\begin{array}{l}\text { Mode of hospitalization: } \\
\text { planned vs urgent }\end{array}$ & 0.19 & 0.05 & 0.77 & 0.02 \\
\hline Hospitalization in the last year & 64.17 & 7.29 & 564.75 & $<0.001$ \\
\hline $\begin{array}{l}\text { Hospital ward: } \\
\text { cardiac vs IM }\end{array}$ & 0.2 & 0.08 & 0.52 & $<0.001$ \\
\hline
\end{tabular}

A p-value $<0.05$ is considered statistically significant. AF - atrial fibrillation; CKD - chronic kidney disease; $\mathrm{Cl}$ - confidence interval; IM - internal medicine; LVEF - left ventricle ejection fraction; MRA - mineralocorticoid antagonism; OR - odds ratio.

in $17.9 \%$ of the hospitalized HF patients $(n=38)$, LBBB with QRS duration $>120$ ms was registered in 12-lead ECG. Most of them were hospitalized in the cardiac ward $(\mathrm{n}=31$; 81.6\%). About half of patients with LBBB $(n=20 ; 52.6 \%)$ had reduced EF (LVEF $\leq 35 \%)$.

Atrial fibrillation was observed in $50.9 \%$ of the hospitalized patients $(\mathrm{n}=109)$ and more often in cardiac ward patients (52.5\% vs 48\%), although not statistically significantly. In AF patients, the median baseline HR on admission was $80 \mathrm{bpm}$ (IQR: 60-106; $\mathrm{HR}_{\max }-160 \mathrm{bpm}$ ) and at discharge $70 \mathrm{bpm}$ (IQR: 60-80; $\mathrm{HR}_{\max }-120 \mathrm{bpm}$ ).

Ischemic etiology of HF was present in $31.3 \%$ of patients ( $n=67$ ). Regarding non-ischemic etiology, arterial hypertension was present in $49 \%$ of patients $(n=105), 38.8 \%$ had valvular disease $(n=83), 7.5 \%$ had congestive cardiomyopathy $(\mathrm{n}=16)$, and $8.4 \%$ had other etiology, namely, toxic cardiomyopathy or tachyarrhythmic cardiomyopathy.

Coronary angiography was performed in $10 \%$ of the cardiac patients $(n=22)$ and slightly more than a half of them ( $\mathrm{n}=13 ; 59 \%$ ) showed no significant atherosclerosis in the coronary arteries; in 1 case, the myocardial bridge was observed, and in the other one, percutaneous coronary intervention and CABG surgery were performed. Some of the cardiac ward patients also underwent dobutamine stress echocardiography (DSE). Patients from the study group were also qualified for coronary computed tomography angiography $(n=6)$ and cardiac magnetic resonance imaging.

Most of the patients $(n=145 ; 67.8 \%)$ were hospitalized for 3-8 days, but significantly shorter in the cardiac ward than in the IM ward (Table 2). As opposed to cardiac ward patients, all IM ward patients were hospitalized immediately (Table 2). Most of the studied patients ( $\mathrm{n}=154$; $72 \%)$ were hospitalized due to HF for the first time. For most of them ( $\mathrm{n}=93 ; 60.4 \%)$, it was hospitalization due to HF exacerbation, but for 61 patients (39.6\%), it was hospitalization due to acute HF de novo. Additionally, 8 patients (5.2\%) with acute HF de novo also had LVEF $\leq 35 \%$ during current hospitalization. Sixty patients were rehospitalized; for 18 of them (30\%), the rehospitalization took place within 1 month after initial discharge and for 33 of them (55\%) within 3 months after initial discharge. Twelve patients $(20 \%)$ were readmitted to hospital after 6 months. For the majority of the rehospitalized patients $(n=50 ; 83 \%)$, current hospitalization was the $2^{\text {nd }}$ or $3^{\text {rd }}$ HF hospitalization.

Compared to the patients hospitalized for the first time, the rehospitalized patients were more likely to have AF, 
LVEF $\leq 40 \%$, ischemic etiology of $\mathrm{HF}$, history of myocardial infarction, CKD, and 3-8 accompanying diseases (for all, $\mathrm{p}<0.05$ ). These patients had lower SBP (mean: $133.42 \mathrm{vs}$ 126.24 mm Hg; $\mathrm{p}=0.032$ ) and diastolic blood pressure (DBP) (mean: 78.82 vs $75.00 \mathrm{~mm} \mathrm{Hg;}=0.04$ ) on admission, had more frequently at least $1 \mathrm{HF}$ hospitalization in the past year $(1.5 \%$ vs $40.1 \%$; $\mathrm{p}<0.001)$, their hospitalizations were longer (mean: 5.30 vs 7.56 days; $\mathrm{p}<0.001$ ), they were more frequently hospitalized urgently $(77.6 \%$ vs $94.6 \% ; \mathrm{p}=0.001)$ and admitted to IM ward $(20.9 \%$ vs $41.5 \% ; \mathrm{p}=0.006)$.
The characteristics of the studied patients related to rehospitalization and/or death are presented in Table 4. The mortality rate was higher for IM ward patients $(\mathrm{p}<0.001)$, both during and after hospitalization (Table 2).

The univariate analysis presents the following significant variables for a higher risk of rehospitalization and/or death: ischemic heart disease, LVEF $\leq 40 \%$, AF, arterial hypertension, valvular disease, CKD, number of comorbidities, MRA therapy, mode of hospitalization, hospitalization in the last year, and hospitalization in the IM ward. The independent predictors of a higher risk of rehospitalization

Table 4. Characteristics of the study population related to rehospitalization and/or death

\begin{tabular}{|c|c|c|c|}
\hline Variables & No rehospitalization and/or death & Rehospitalization and/or death & $\mathrm{p}$-value \\
\hline All patients, n [\%] & $67(31.3)$ & $147(68.7)$ & - \\
\hline Age [years], mean $\pm S D$ & $71.6 \pm 11.81$ & $73.96 \pm 13.36$ & 0.216 \\
\hline LVEF $\leq 40 \%, n[\%]$ & $17(28.8)$ & $62(56.9)$ & 0.001 \\
\hline HR on admission [bpm], mean \pm SD & $79.3 \pm 17.68$ & $84.29 \pm 20.42$ & 0.086 \\
\hline $\mathrm{HR}$ at discharge $[\mathrm{bpm}]$, mean $\pm \mathrm{SD}$ & $70.27 \pm 9.61$ & $72.64 \pm 10.64$ & 0.121 \\
\hline \multicolumn{4}{|c|}{ Comorbidities } \\
\hline Number of comorbidities: 0-3, n [\%] & $54(80.6)$ & $81(55.1)$ & 0.001 \\
\hline Number of comorbidities: 3-8, n [\%] & $13(19.4)$ & $66(44.9)$ & 0.001 \\
\hline Coronary artery disease, n [\%] & $21(31.3)$ & $79(53.7)$ & 0.004 \\
\hline History of myocardial infarction, n [\%] & $8(11.9)$ & $46(31.3)$ & 0.004 \\
\hline $\mathrm{AF}, \mathrm{n}[\%]$ & $25(37.3)$ & $84(57.1)$ & 0.011 \\
\hline $\mathrm{DM}, \mathrm{n}[\%]$ & $24(35.8)$ & $66(44.9)$ & 0.272 \\
\hline Arterial hypertension, n [\%] & $57(85.1)$ & $105(71.4)$ & 0.047 \\
\hline$C K D, n[\%]$ & $6(9.0)$ & $42(28.6)$ & 0.003 \\
\hline COPD, n [\%] & $5(7.5)$ & $25(17.0)$ & 0.098 \\
\hline Cancer, n [\%] & $5(7.5)$ & $10(6.8)$ & 1.00 \\
\hline \multicolumn{4}{|c|}{ Etiology of HF } \\
\hline Ischemic heart disese, n [\%] & $8(11.9)$ & $59(40.1)$ & $<0.001$ \\
\hline Hypertension, n [\%] & $46(68.7)$ & $59(40.1)$ & $<0.001$ \\
\hline Valvular disease, n [\%] & $25(37.3)$ & $58(39.5)$ & 0.883 \\
\hline Congestive cardiomyopathy, n [\%] & $2(3.0)$ & $14(9.5)$ & 0.160 \\
\hline Other ${ }^{\mathrm{a}}, \mathrm{n}[\%]$ & $8(11.9)$ & $10(6.8)$ & 0.322 \\
\hline \multicolumn{4}{|c|}{ Current hospitalization } \\
\hline Urgent hospitalization, n [\%] & $52(77.6)$ & $139(94.6)$ & 0.001 \\
\hline Length of hospitalization [days], mean $\pm \mathrm{SD}$ & $5.3 \pm 2.81$ & $7.56 \pm 4.17$ & 0.001 \\
\hline Hospitalization in the last year, n [\%] & $1(1.5)$ & $59(40.1)$ & $<0.001$ \\
\hline \multicolumn{4}{|c|}{ Pharmacotherapy } \\
\hline ACEl, n [\%] & $42(62.7)$ & $87(59.2)$ & 0.738 \\
\hline $\mathrm{ARB}, \mathrm{n}[\%]$ & $15(22.4)$ & $17(11.6)$ & 0.064 \\
\hline$\beta$-blockers, n [\%] & $61(91.0)$ & $118(80.3)$ & 0.076 \\
\hline MRA, n [\%] & $36(53.7)$ & $99(67.3)$ & 0.078 \\
\hline Ivabradine, n [\%] & $2(3.0)$ & $7(4.8)$ & 0.815 \\
\hline Diuretics, n [\%] & $53(79.1)$ & $119(81.0)$ & 0.886 \\
\hline
\end{tabular}

Data is presented as mean \pm standard deviation (SD) or number (percentage). A p-value $<0.05$ is considered statistically significant. ${ }^{a}$ toxic cardiomyopathy, tachyarrhytmic cardiomyopathy; ACEI - angiotensin-converting-enzyme inhibitors; AF - atrial fibrillation; ARB - angiotensin receptor blockers; CKD - chronic kidney disease; COPD - chronic obstructive pulmonary disease; DM - diabetes mellitus; HF - heart failure; HR - heart rate; LVEF - left ventricle ejection fraction; MRA - mineralocorticoid antagonism. 
Table 5. Analysis of standard heart failure (HF) pharmacotherapy

\begin{tabular}{|l|c|c|c|c|}
\hline \multicolumn{1}{|c|}{ Variables } & Yes & $<50 \%$ of target dose & $\geq 50 \%$ of target dose \\
\hline ACEI, $n$ [\%] & $129(60.3)$ & $67(51.9)$ & $37(28.7)$ \\
\hline ARB, $n$ [\%] & $32(15.1)$ & $12(37.5)$ & $19(59.4)$ \\
\hline B-blockers, $n$ [\%] & $179(83.6)$ & $87(48.6)$ & $74(41.3)$ \\
\hline MRA, $n$ [\%] & $135(63.1)$ & $4(3.0)$ & $18(10.1)$ \\
\hline
\end{tabular}

A p-value $<0.05$ is considered statistically significant. ACEI - angiotensin-converting-enzyme inhibitors; ARB - angiotensin receptor blockers; MRA - mineralocorticoid antagonism.

and/or death in the multivariate regression model are presented in Table 3.

At discharge, over $90 \%$ of cardiac ward patients and only $60 \%$ of IM ward patients were referred to outpatient cardiac clinics ( $\mathrm{p}<0.001)$. All LBBB patients had a cardiologist's consultation during the 3-month follow-up after the HF hospitalization, regardless of the hospital department (IM vs cardiac). Slightly over a half of cardiac ward patients (56.9\%) and none of IM ward patients had their $1^{\text {st }}$ ambulatory appointment in a period shorter than 3 months post-discharge (Table 2).

The majority of the hospitalized patients were under the optimal medical treatment of HF (ACEI/ARB, $\beta$-blockers, MRA). More than $80 \%$ of all hospitalized patients and more than $90 \%(n=101)$ of AF patients were taking $\beta$-blockers. The percentage of patients receiving ACEI or ARB reached more than $75 \%$ (Table 5 ). However, cardiac ward patients more frequently than IM ward patients received $\beta$-blockers, diuretics, ARB, and MRA (Table 2). None of IM ward patients, and only 4 patients in the cardiac ward, received ivabradine (Table 2).

Despite the fact that $\beta$-blockers were prescribed most often, in the majority of cases, they were prescribed in $<50 \%$ of the target dose. Only $10 \%$ of all studied patients received the target dose of $\beta$-blockers for HF. The population of AF patients, in the majority of cases (53.5\%; $\mathrm{n}=54$ ), also received $\beta$-blockers in $50 \%$ or $<50 \%$ of the target dose. The others $(33.6 \% ; n=34)$ received $\beta$-blockers in $>50 \%$ of the target dose and only $12.87 \%(n=13)$ of AF patients were under the target dose of $\beta$-blockers. Otherwise, about half of AF patients $(51.4 \% ; \mathrm{n}=56)$ had therapy with digoxin as concomitant therapy.

Similarly, only $20 \%$ of patients received the ACEI target dose and less than 5\% received the ARB target dose. In the studied population, only in MRA treatment, over $70 \%$ of patients reached the recommended target dose (Table 5). However, cardiac ward patients more frequently than IM ward patients received diuretics in the target dose $(30 \%$ vs $7 \%$; $<<0.001)$.

\section{Discussion}

The presented analysis is to our best knowledge the first analysis of Polish HF patients distinguishing between admission wards. No other project in Poland compared the in-hospital and post-discharge management of HF patients in relation to hospital admission wards - cardiac vs IM. This analysis showed differences in guideline implementation between the 2 studied hospital wards.

The HF population from our study is similar to the general Polish HF population analyzed in 2012, in terms of the mode of admission and median length of hospitalization. ${ }^{13}$ However, in the 2012 report, $75 \%$ of HF patients were hospitalized in IM wards and $22 \%$ in cardiac wards. ${ }^{13}$ In our study, these proportions are different, which is related to the high specialization of the cardiac department in HF. Similarly to the 2012 HF analysis, we found longer hospitalization in the IM ward than in the cardiac ward (median of 7 and 6 days in the 2012 report vs 7.56 and 5.30 days in our study, respectively). Also, similarly to the 2012 analysis, the majority of HF patients were admitted due to acute decompensation of HF ( $83 \%$ of all HF hospitalizations in 2012 vs $89 \%$ in the studied population). ${ }^{13}$ Most of the studied patients $(\mathrm{n}=154 ; 72 \%)$ were hospitalized due to HF for the first time. For 61 patients (39.6\%), it was hospitalization due to acute HF de novo. Additionally, 8 patients (5.2\%) with acute HF de novo had also LVEF $\leq 35 \%$ during current hospitalization. These patients, after 3 months of optimal medical treatment, should be reevaluated by a cardiologist, taking into account the ECG analysis and echocardiography measurement of LVEF, before the final decision on electrotherapy.

From the HF exacerbation subgroup, 54 patients also had LVEF $\leq 35 \%$ during current hospitalization. Taking into account 3 months of optimal pharmacological therapy for HF, the ECG analysis and ongoing clinical indications, the patients should be potentially qualified for electrotherapy. Additionally, in 17.9\% of the hospitalized HF patients $(\mathrm{n}=38)$, LBBB with QRS duration $>120 \mathrm{~ms}$ was registered in 12-lead ECG. About half of patients with LBBB ( $\mathrm{n}=20 ; 52.6 \%$ ) had reduced EF (LVEF $\leq 35 \%)$. This is an important group of HF patients in terms of qualifying for electrotherapy. According to the valid guidelines in the period of our study (the 2013 ESC guidelines on cardiac pacing and cardiac resynchronization therapy), a cardiac resynchronization therapy and defibrillator (CRT-D) should be considered in patients with LBBB with QRS duration of 120-150 ms (class of recommendation 1, level of evidence B), or $>150 \mathrm{~ms}$ (class of recommendation 1 , level of evidence A), with chronic HF and LVEF $\leq 35 \%$, who 
remain in NYHA functional class II, III and ambulatory IV despite 3 months of optimal medical treatment. ${ }^{1,18}$

In 2012, the overall death rate for HF patients in Poland was $11 \% .^{13}$ In our short-term analysis of hospitalization and the 3-month period after discharge, the overall death rate was $11.2 \%$. The mortality rate was higher for IM ward patients $(\mathrm{p}<0.001)$, both during and after hospitalization (Table 2).

So far, European and Canadian studies have shown specialty-related differences in the management and prognosis of HF patients. ${ }^{19-22}$ In countries such as Italy, Spain and Canada, the admission ward was related to a clear dissimilarity in the process of diagnosis and treatment. ${ }^{19-22}$ In these studies, as well as in our analysis, IM ward patients were older, had more co-morbidities and their hospitalizations were longer.

According to the results of our analysis, HF management in Poland, compared to other European countries and Canada, seems to be similar in terms of differences between IM and cardiac departments. In a study from Italy, similar to our population, patients treated by cardiologists were more likely to be prescribed ACEI and $\beta$-blockers at discharge than IM ward patients (100\% vs $74 \%$ and $41 \%$ vs $4 \%$, respectively). ${ }^{20}$ Patients receiving a follow-up by cardiologists were younger than IM ward patients (median: Canada - 71.7 vs 75.8 years; Italy - 70 vs 79 years, Spain - 72.5 vs 77.4 years, respectively).

Unlike in Poland, in other analyzed countries, there was no statistical significance in terms of in-hospital and postdischarge mortality in relation to the type of admission ward.

Post-discharge care in HF patients with regular ambulatory visits is strongly indicated. ${ }^{1}$ Based on the new ESC guidelines, the HF patient should be examined by a general practitioner (GP) within 1 week of discharge and by the hospital cardiology team within 2 weeks of discharge. ${ }^{1}$ However, none of the abovementioned European and $\mathrm{Ca}$ nadian studies focused on post-discharge care. ${ }^{18-21}$ Another important observation from our study is that cardiac ambulatory care was more often recommended in the case of patients hospitalized in cardiac wards as compared to IM wards (90\% vs $60 \%$ ). In our study, the number of referrals of the cardiac patients to outpatient cardiac care did not differ significantly from the general HF population results in 2012, in contrast to IM patients. Compared to the 2012 analysis, in our study, more of all hospitalized patients were referred to ambulatory cardiac care after discharge ( $80 \%$ in our study vs $70 \%$ in the 2012 report).${ }^{13}$ In our study, all LBBB patients had a consultation with a cardiologist during the 3-month follow-up after HF hospitalization, regardless of the hospital department (IM vs cardiac). Compared to the general hospitalized HF population in this study, this was a very good result, because at discharge over $90 \%$ of cardiac ward patients and only $60 \%$ of IM ward patients were referred to an outpatient cardiac clinic $(\mathrm{p}<0.001)$.
Another important issue is that patients hospitalized in the IM ward were more likely to have a worse baseline general condition, e.g., they more often had CKD (although not statistically significantly), had a significantly higher mean age (by almost 10 years) and were more often admitted urgently, e.g., due to infection.

Many variables of significance for cardiac events in HF are described in the literature. One of the most important is older age. In the elderly, the most common cause of hospitalization is $\mathrm{HF}$. In people over 70 years of age, $\mathrm{HF}$ affects $1 / 10$ of seniors and is the leading cause of death in this age group. ${ }^{1,23-25}$ In seniors over 80 years of age, comorbidities also have an important prognostic value for annual prognosis in chronic HF. ${ }^{25}$ In our study, a worse baseline general condition with comorbidities, such as ischemic heart disease, AF and CKD, are independent variables for longer hospitalization and/or mortality.

It should also be emphasized that there are differences in characteristics and diagnostic procedures performed in cardiac and IM wards. In IM departments, only $43 \%$ of patients underwent, at the same time, echocardiography with the measurement of LVEF and natriuretic peptides. In our study, in the majority of cardiac ward patients, opposite to IM ward patients, the echocardiography and NT-proBNP measurement were performed. It is worth noticing that biomarkers are crucial for the diagnosis and professional management of HF. ${ }^{26}$ In other European studies, patients managed by cardiologists were also more likely than IM wards patients to undergo echocardiography (Italy: $89-92 \%$ vs $37-54.8 \%) .{ }^{20,21}$

Compared to our findings, in EURObservational Research Programme The Heart Failure Pilot Survey (ESC HF-Pilot), $\mathrm{BNP} / \mathrm{NT}$-proBNP measurements as well as echocardiography were performed much more frequently in patients hospitalized in our cardiac ward (96\% vs 36.6\% and 98\% vs $75 \%$, respectively). The results were different in the IM ward ( $43 \%$ vs $36.6 \%$, and $43 \%$ vs $75 \%$, respectively). ${ }^{9}$ The studied HF population was burdened with comorbidities similar to those of the individuals from ESC-HF Pilot, most frequently coronary artery disease, hypertension, CKD, and DM. ${ }^{27,28}$

Although the ESC-HF Pilot population $(n=5118)$ differed significantly from our HF population in terms of the admission mode to a cardiac ward (for acute HF - 37\% vs $83.5 \%$ and for chronic HF - $63 \%$ vs $16.5 \%$, respectively), the median length of stay in a cardiac ward in ESC-HF Pilot was higher than in our study (8 vs 5 days, respectively). ${ }^{27}$ It should be highlighted that ESC-HF Pilot included only patients hospitalized in cardiac departments. ESC-HF Pilot population was treated mainly with ACEI and $\beta$-blockers (80\%). However, target doses were reached in $1 / 3-1 / 4$ of the ESC-HF Pilot patients only. Even lower results of the target dose achievement were observed in our study (19.4\% for ACEI and $10 \%$ for $\beta$-blockers).

The Polish population from ESC-HF Pilot was younger compared to our study ( $66 \pm 13.7$ vs $72.2 \pm 12.9$ years, 
respectively). ${ }^{29}$ Angiography confirmed that coronary artery disease was the main etiology of HF in Polish patients from the registry (39\%). The analysis of data from our study showed that, as proven in the ESC-HF Pilot study, ischemic etiology of HF was very common among cardiac ward patients (51\%).

The 3-month death rate for ESC-HF Pilot Polish patients was estimated at about $2.5 \%$, while it was $3 \%$ in other European countries. Meanwhile, it is noteworthy that, in our study, the death rate was at a lower level than in the ESC-HF Pilot study - 2.9\% in-hospital and $1.4 \%$ post-discharge.

A recently published global survey shows the implementation of guideline-recommended HF treatment. ${ }^{30}$ In the QUALIFY survey, as well as in the cardiac HF population from our study, the majority of patients were treated with ACEI (65.7\% vs 62.6\%), $\beta$-blockers (86.7\% vs $89.2 \%)$ and diuretics (83\% vs $86.3 \%)$. Ivabradine has proven its efficacy in reducing hospitalizations for $26 \%$ in the SHIFT study. ${ }^{31}$ In our analysis, it was observed that cardiologists prescribed this drug at discharge to a greater extent than internists, but still with a very low frequency $(26.7 \%$ vs 0 , respectively). In the QUALIFY survey, the number of patients treated with ivabradine was above $33.4 \% .^{30}$

The optimal HF therapy at discharge in our study and in the QUALIFY survey was poor. However, target doses were at a better rate in the QUALIFY survey than in the studied population - $27.9 \%$ vs $19.4 \%$ for ACEI and $14.8 \%$ vs $10.1 \%$ for $\beta$-blockers. ${ }^{30}$

Compared to the QUALIFY registry, the frequency of use of implantable devices, such as ICD or CRT, was also poor in both studies, but at a better rate in QUALIFY survey than in our study $-9.7 \% .^{30}$

A crucial observation from our study is that HF hospitalization in the previous 12 months was the most important risk factor for subsequent hospitalizations. The results of the QUALIFY survey showed that $30.4 \%$ of patients had a history of 2 or more HF hospitalizations. ${ }^{30}$ In the ESC-HF Pilot study, $57 \%$ of HF population had a history of previous hospitalizations and, additionally, $24.75 \%$ of patients were rehospitalized in a 1-year follow-up..$^{27,29}$

This study has some limitations that have to be acknowledged. Firstly, it should be noted that it was a retrospective analysis. Inclusion criteria were based only on diagnostic code I50 in the ICD-10 classification and on the data available in the medical system CliniNET $^{\circledR}$, not on medical assessment.

Other limitations are that the study included only a 3-month period of follow-up and analyzed the adherence score to guideline recommendations for only standard HF treatment according to the ESC recommendations (3 groups of drugs: ACE/ARB, $\beta$-blockers and MRA), and additional ivabradine and diuretics without digoxin or nitrates.

Moreover, we made a hospital ward- and endpoint-related statistical analysis, but it was carried out with the EF value (HFrEF vs HFpEF).
Despite the advances in clinical practice, as documented in our analysis and previous publications, there is still a place for improvement in terms of the diagnosis of HF, determination of prognosis and treatment selection.

In conclusion, the single-center study has shown that the management of HF patients differs significantly depending on the admission ward. The differences include diagnostic procedures, hospitalization, treatment, ambulatory care, and prognosis, showing the advantages of cardiac wards. The presented results of the journey of HF patients indicate the need for improvement in the field of HF care.

\section{References}

1. Ponikowski P, Voors A, Anker S, et al.; ESC Scientific Document Group. 2016 ESC Guidelines for the diagnosis and treatment of acute and chronic heart failure. The Task Force for the diagnosis and treatment of acute and chronic heart failure of the European Society of Cardiology (ESC). Eur Heart J. 2016;37(27):2129-2200.

2. OECD. Health at a Glance 2015. OECD Indicators. 2015. doi:10.1787/ health_glance-2015-en

3. Mosterd A, Hoes AW. Clinical epidemiology of heart failure. Heart. 2007;93(9):1137-1146.

4. Mozaffarian D, Benjamin EJ, Go AS, et al.; American Heart Association Statistics Committee, Stroke Statistics Subcommittee. Heart disease and stroke statistics - 2016 update: A report from the American Heart Association. Circulation. 2016;133(4):e38-360.

5. Lloyd-Jones DM, Larson MG, Leip EP, et al.; Framingham Heart Study. Lifetime risk for developing congestive heart failure: The Framingham Heart Study. Circulation. 2002;106(24):3068-3072.

6. Fonarow GC, Abraham WT, Albert NM, et al. Association between performance measures and clinical outcomes for patients hospitalized with heart failure. JAMA. 2007;297(1):61-70.

7. Dharmarajan $\mathrm{K}$, Hsieh AF, Lin Z, et al.; OPTIMIZE-HF Investigators and Hospitals. Diagnosis and timing of 30-day readmissions after hospitalization for heart failure, acute myocardial infarction, or pneumonia. JAMA. 2013;309(4):355-363.

8. Gheorghiade M, Vaduganathan M, Fonarow GC, Bonow RO. Rehospitalization for heart failure: Problems and perspectives. J Am Coll Cardiol. 2013;61(4):391-403.

9. Maggioni AP, Dahlstrom U, Filippatos G, et al.; Heart Failure Association of the European Society of Cardiology (HFA). EURObservational Research Programme: Regional differences and 1-year follow-up results of the Heart Failure Pilot Survey (ESC-HF Pilot). Eur J Heart Fail. 2010;15(7):808-817.

10. Solomon SD, Dobson J, Pocock S, et al.; Candesartan in Heart failure: Assessment of Reduction in Mortality and morbidity (CHARM) Investigators. Influence of nonfatal hospitalization for heart failure on subsequent mortality in patients with chronic heart failure. Circulation. 2007;116(13):1482-1487.

11. Roger VL, Go AS, Lloyd-Jones DM, et al.; American Heart Association Statistics Committee and Stroke Statistics Subcommittee. Heart disease and stroke statistics - 2012 update: A report from the American Heart Association. Circulation. 2012;125(1):e2-e220.

12. Fonarow GC, Stough WG, Abraham WT, et al.; OPTIMIZE-HF Investigators and Hospitals. Characteristics, treatments and outcomes of patients with preserved systolic function hospitalized for heart failure: A report from the OPTIMIZE-HF Registry. J Am Coll Cardiol. 2007;50(8):767-768.

13. Gierczyński J, Gryglewicz J, Karczewicz E, Zalewska H. Heart Failure - Analysis of the Economic and Social Costs. Warszawa, Poland: Instytut Zarządzania w Ochronie Zdrowia Uczelni Łazarskiego w Warszawie; 2013.

14. The Criteria Committee of the New York Heart Association. Nomenclature and Criteria for Diagnosis of Diseases of the Heart and Great Vessels. $9^{\text {th }}$ ed. Boston, MA: Little Brown \& Co.; 1994:253-256. 
15. Lang RM, Badano LP, Mor-Avi V, et al. Recommendations for cardiac chamber quantification by echocardiography in adults: An update from the American Society of Echocardiography and the European Association of Cardiovascular Imaging. J Am Soc Echocardiogr. 2015;28(1):1-39.

16. Kolh P, Windecker S, Alfonso P, et al. 2014 ESC/EACTS Guidelines on myocardial revascularization: The Task Force on Myocardial Revascularization of the European Society of Cardiology (ESC) and the European Association for Cardio-Thoracic Surgery (EACTS). Developed with the special contribution of the European Association of Percutaneous Cardiovascular Interventions (EAPCI). Eur J Cardiothorac Surg. 2014;46(4):517-592.

17. McMurray JJ, Adamopoulos S, Anker SD, et al.; ESC Committee for Practice Guidelines. ESC Guidelines for the diagnosis and treatment of acute and chronic heart failure 2012: The Task Force for the Diagnosis and Treatment of Acute and Chronic Heart Failure 2012 of the European Society of Cardiology. Developed in collaboration with the Heart Failure Association (HFA) of the ESC. Eur Heart J. 2012;33 (14):1787-1847.

18. Brignole M, Auricchio A, Baron-Esquivias G, et al.; 2013 ESC Guidelines on cardiac pacing and cardiac resynchronization therapy: The Task Force on cardiac pacing and resynchronization therapy of the European Society of Cardiology (ESC). Developed in collaboration with the European Heart Rhythm Association (EHRA). Europace 2013;15(8):1070-1118.

19. Garcia Castelo A, Muniz Garcia J, Sesma Sanches P, Castro Beiras A Grupo de estudio INCARGAL. Use of diagnostic and therapeutic resources in patients hospitalized for heart failure: Influence of admission ward type (INCARGAL Study) [in Spanish]. Rev Esp Cardiol. 2003;56(1):49-56.

20. Bellotti P, Badano LP, Acquarone N, et al.; OSCUR Investigators. Specialty-related differences in the epidemiology, clinical profile, management and outcome of patients hospitalized for heart failure; the OSCUR study. Oucome dello Scompenso Cardiaco in relazione all'Utilizzo delle Risore. Eur Heart J. 2001;22(7):596-604.
21. Di Lenarda A, Scherillo M, Maggioni AP, et al.; TEMISTOCLE Investigators. Current presentation and management of heart failure in cardiology and internal medicine hospital units: A tale of 2 worlds - the TEMISTOCLE study. Am Heart J. 2003;146(4):E12.

22. Petrovic V, Sirar I, Valerie AP. A tale of two specialties: Differences between heart failure patients admitted to internal medicine and cardiology. Can J Gen Intern Med. 2013;8 (1):4-7.

23. Wojtczak-Soska K, Sakowicz A, Pietrucha T, Lelonek M. Soluble ST2 protein in the short-term prognosis after hospitalization in chronic systolic heart failure. Kardiol Pol. 2014;72(8):725-734.

24. Lelonek M. Heart failure and rehospitalization [in Polish]. Folia Cardiol. 2016;11(1):37-46.

25. Cichocka-Radwan A, Lelonek M. Annual prognostic factors in chronic heart failure in patients over 80 years old. Kardiol Pol. 2017;75:164-173.

26. Solnica B. Biomarkers in heart failure: Ready for use? Pol Arch Med Wewn. 2015;125(6):398-399.

27. Maggioni AP, Dahlstrom U, Filippatos G, et al.; Heart Failure Association of ESC (HFA). EURObservational Research Programme: The Heart Failure Pilot Survey (ESC-HF Pilot). Eur J Heart Fail. 2010;12(10):1076-1084.

28. Deursen VM, Urso R, Laroche C, et al. Co-morbidities in patients with heart failure: An analysis of the European Heart Failure Pilot Survey. Eur J Heart Fail. 2014;16(1):103-111.

29. Sosnowska-Pasiarska B, Bartkowiak R, Wożakowska-Kapłon B, et al. Population of Polish patients participating in the Heart Failure Pilot Survey (ESC-HF Pilot). Kardiol Pol. 2013;71(3):234-240.

30. Komajda M, Anker S, Cowie M, et al.; QUALIFY Investigators. Physician's adherence to guideline-recommended medications in heart failure with reduced ejection fraction: Data from the QUALIFY global survey. Eur J Heart Fail. 2016;18(5):514-522.

31. Swedberg K, Komajda M, Bohm M, et al.; SHIFT Investigators. Ivabradine and outcomes in chronic heart failure (SHIFT): A randomized placebo-controlled study. Lancet. 2010;376(9744):875-885. 